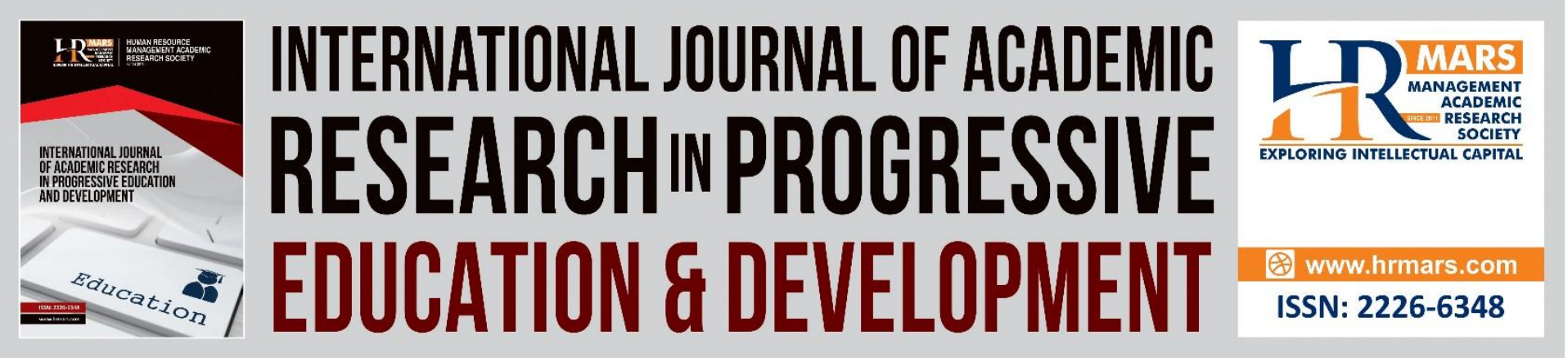

\title{
Semantic Challenges Caused by Abbreviations of Arabic Economic and Business Terms for Undergraduates in China
}

Ma Shuhan, Mohd Azidan Abdul Jabar, Ng Chwee Fang

To Link this Article: http://dx.doi.org/10.6007/IJARPED/v11-i1/11937 DOI:10.6007/IJARPED/v11-i1/11937

Received: 12 November 2021, Revised: 13 December 2021, Accepted: 30 December 2021

Published Online: 15 January 2022

In-Text Citation: (Shuhan et al., 2022)

To Cite this Article: Shuhan, M., Jabar, M. A. A., \& Fang, N. C. (2022). Semantic Challenges Caused by Abbreviations of Arabic Economic and Business Terms for Undergraduates in China. International Journal of Academic Research in Progressive Education and Development, 11(1), 120-133.

Copyright: (C) 2022 The Author(s)

Published by Human Resource Management Academic Research Society (www.hrmars.com)

This article is published under the Creative Commons Attribution (CC BY 4.0) license. Anyone may reproduce, distribute, translate and create derivative works of this article (for both commercial and non-commercial purposes), subject to full attribution to the original publication and authors. The full terms of this license may be seen

at: http://creativecommons.org/licences/by/4.0/legalcode

\section{Vol. 11(1) 2022, Pg. 120 - 133}

Full Terms \& Conditions of access and use can be found at http://hrmars.com/index.php/pages/detail/publication-ethics 


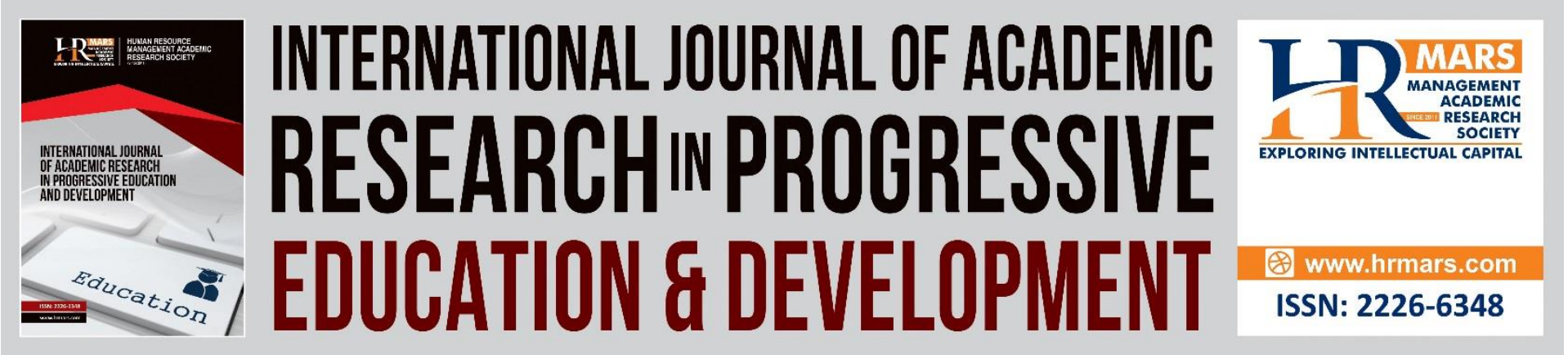

\title{
Semantic Challenges Caused by Abbreviations of Arabic Economic and Business Terms for Undergraduates in China
}

\author{
Ma Shuhan, Mohd Azidan Abdul Jabar, Ng Chwee Fang \\ Faculty of Modern Languages and Communication, Universiti Putra Malaysia \\ Email: mashuhan55@gmail.com
}

\begin{abstract}
The economic usefulness of abbreviations has become essential as language tools in human society, especially for international economic and business activities. This study has explored the semantic challenges of abbreviations of Arabic economic and business terms for thirdgrade undergraduates majoring in Arabic language without basic backgrounds in the economy and business in China. The present study adopted a quantitative study design to test 30 students' abilities in understanding abbreviations. The data analysis used simple mathematical statistics to calculate results and comprehensive analysis within terminological frameworks with interdisciplinary semantic theories to mainly analyze correct answers and students' answers. Thus, we have found that three-quarters of students faced varying degrees of semantic challenges in the abbreviations of Arabic economic and business terms. In this regard, the current study will improve students' understanding of abbreviations, and remind instructors in the courses of Arabic for business purposes to explain such knowledge.
\end{abstract}

Keywords: Semantic Challenges, Abbreviations, Arabic Terms, Undergraduates

\section{Introduction}

Over the last few decades, modern languages have shown a trend toward 'economical use', which entails transmitting the most amount of data per unit of time (Ulitkin, Filipova, Ivanova, \& Babaev, 2020). Currently, an "explosive increase in the usage of acronyms" in languages has been witnessed (Ulitkin, Filipova, Ivanova, \& Babaev, 2020). This tendency appears in many interdisciplinary languages, especially for one of the items in Arabic for business purposes, Arabic economic and business terms.

Arabic economic and business terms are compound words as well as multi-word expressions that in economic and business contexts (Vasuchenko, 2011) are given specific concepts based on the Arabic language. Those terms can represent a particular concept with completeness and accuracy, but sometimes they are cumbersome in the process of usage, so that short versions are needed (Ulitkin, Filipova, Ivanova, \& Babaev, 2020). Thus, such forms can reduce the time (Sigacheva, Makayev, Makayeva, \& Gainanova, 2021) of business work and make both parties of the trade improve work efficiency. 
"An abbreviation is a short way of writing a word or a phrase that could also be written out in full" (Trask, 1997). So, for instance, "BBC" is abbreviated from British Broadcasting Corporation (Trask, 1997), which is familiar with people in daily life. "If one uses them effectively, they not only reduce space, but also facilitate the reading and understanding of a text" (Ulitkin, Filipova, Ivanova, \& Babaev, 2020). Simultaneously, in Arabic economic and business terms, abbreviations are one of the important sources of terminology that cannot be ignored, which are used in the activities of the economy and business. (Zhao \& Wu, 2010; Han, 2019). Representatively, the Incoterms (International Commercial Terms) are "a series of pre-defined commercial terms defining the key parts of freight forwarding" (Incoterms 2020 Certificate (INCO) Online - ICC Academy, 2021), which are widely adopted in Arabic economic and business terms.

Although the form of abbreviations looks like it can be used simply and easily, it is aware that the abbreviations convey contents with high ambiguity and cannot be ignored, particularly for those carrying fewer characters (Olga, Anna, \& Natalia, 2015). Thus, we assume such ambiguities also appear in Arabic economic and business terms. In this light, abbreviations of Arabic economic and business terms carrying the forms and full denominations and meanings would cause some challenges for undergraduates, especially for those who major in Arabic language, but do not have enough knowledge reserves in the fields of economy and business (Huang, 2015).

Therefore, the objectives of present study would be:

- To identify several semantic challenges caused by abbreviations of Arabic economic and business terms for third-grade undergraduates majoring in Arabic language in China;

- To affect the further study of students in understanding and using Arabic economic and business terms that appear in the textbook.

\section{Literature Review}

In modern language studies, most of professional terms were expressed using phrases or complex words. (Sigacheva, Makayev, Makayeva, \& Gainanova, 2021). Shortened lexical units as a specific linguistic phenomenon have attracted the attention of many researchers (Olga, Anna, \& Natalia, 2015). Although the present literature review was very limited, we have still identified the abbreviation's definition and current research orientations in the literature. Such literature would support us to find some gaps to conduct this study.

General research has regarded abbreviations as lexical units in linguistics, due to their being quite often registered in lexicographical sources (Ulitkin, Filipova, Ivanova, \& Babaev, 2020). According to abbreviations' graphical and sound representation, they were divided into abbreviations and acronyms in English language. Referring to the online Oxford English Dictionary (Abbreviation, n.d.), "an abbreviation is a shortened form of a word or phrase", while "an acronym is an abbreviation formed from the initial letters of other words and pronounced as a single word" (Acronym, n.d.). Although both abbreviations and acronyms were made up of the first letter of a phrase, they differed in one important way: acronyms cannot be pronounced as individual words. This fact has led to differences in the use of abbreviations and acronyms in language and speech. Also, it was important to note that, in some cases, it was impossible to determine whether a shortened word was an acronym or an 
abbreviation or whether it was possible to shorten this or that phrase (Ulitkin, Filipova, Ivanova, \& Babaev, 2020).

The general function of abbreviations was to reduce space in written text presentations and saving time when spoken orally, so as to avoid duplication of sophisticated words and phrases, or to correspond to common use in specific forms of speech (Alla, Polina, Elizaveta, \& Olga, 2020). From a semiotic point of view, abbreviations took a function of symbols in scientific and technical texts, after they were fully mentioned for the first time (after the full term) (Ulitkin, Filipova, Ivanova, \& Babaev, 2020). Moreover, abbreviations' unique functions have contributed to their successful implementation as part of the language at the discourse level, according to the regular standards in the language and cultural environment (Alla, Polina, Elizaveta, \& Olga , 2020). As for abbreviations' nominative function, it was expanded as they have given new names to well-known concepts and objects (Zerkina, Kostina, \& Pitina, 2015).

As for abbreviation semantics, it represented a very complex phenomenon with specific connotations (Zerkina, Kostina, \& Pitina, 2015). To study it, we should consider data "taken from other sciences - lexicology, grammar, stylistics, phonetics, history of the language, philosophy, history, logic, country studies, etc." (Zerkina, Kostina, \& Pitina, 2015). Moreover, the construction of abbreviation semantics occurred concurrently with the abbreviation process (Zerkina, Kostina, \& Pitina, 2015). For such reasons, much remains unknown about the lexical semantic features of abbreviations, as well as the semantic regularities of their development (Olga, Anna, \& Natalia, 2015).

Nevertheless, from a semantic view, abbreviations had the linguistic properties of words, and held their own lexical phraseological and morphological syntactic peculiarities, owing to their semantic independence and manifesting linguistic peculiarities different from those of the prototype (Alla , Polina, Elizaveta, \& Olga , 2020). Moreover, several studies attempted to apply some relevant semantic theories in practice. For example, abbreviations have served as graphical visualizers of new terms, drawing the reader's attention to the related sections of the text, as well as markers of the text's information space and organizing text architectonics (Ulitkin, Filipova, Ivanova, \& Babaev, 2020). Simultaneously, the abbreviation should generally follow the criteria for translating vocabulary, which were based on semantic correspondences between the correlative units of a given pair of languages. The proximity to terms, i.e., the absence of connotations, underlines the importance of conveying the semantic meaning of abbreviations even more. (Ulitkin, Filipova, Ivanova, \& Babaev, 2020). Other examples like "hidden" semantics of abbreviations, only the context can assist us monitor the semantic growth of abbreviations and the transmitting of prospective semes of an abbreviation's meaning. Because any sporadic modifications, prior to being fixed in the language, are applied in speech in a written or oral generative context (Zerkina, Kostina, \& Pitina, 2015). Otherwise stated, one of effective methods to study abbreviations was the "semantic triangle". Specifically, an abbreviation unit has the power to name, as evidenced by a three-component relation, thought-symbol-object (referent): an abbreviation, as a symbol, names an object with categorical attributes of a created idea. As an example, any lexical abbreviation or term in any language may be used (Zerkina, Kostina, \& Pitina, 2015).

Other orientations of abbreviations' problems have been studied. For example, polysemous abbreviations have created extra challenges in recognizing their semantic content (Ulitkin, 
Filipova, Ivanova, \& Babaev, 2020). Particularly in medical translations, the main was that the same abbreviation could have different meanings depending on the disease, anatomy, or procedure being discussed (Olga, Anna, \& Natalia, 2015). At the linguistic level of translation problems, abbreviation fusion and homophony have acted as destructive interference at the level of word formation, which has stemmed from the formation and variability in connection with the linguistic and cultural traditions of British and American scientific literature (Ulitkin, Filipova, Ivanova, \& Babaev, 2020). Moreover, it was hard to reach a fragile balance between the equivalence of a source text and the used translation strategies in the process of translating abbreviations (Ulitkin, Filipova, Ivanova, \& Babaev, 2020). Especially, using abbreviations in scientific discourse was associated with the presence of a common terminological base (research experience) and personal experience. Translating abbreviation caused mistakes due to in the case of a significant discrepancy in background knowledge and skills (Ulitkin, Filipova, Ivanova, \& Babaev, 2020).

The current studies have also adopted abbreviations combined with other specific fields. For instance, Fazeli (2010) applied the abbreviation and acronym strategy for vocabulary learning in second/foreign language learning procedures. Meanwhile, Fazeli (2010) pointed out that using abbreviations and acronyms as codes for presenting the meaning of words would help learners achieve greater success in vocabulary learning activities. As well, Méndez \& Alcaraz (2015) presented the abbreviation as one of the most characteristic and recurrent features in the titling construction of English-medium astrophysics. In this light, abbreviations' proper use should be regulated by teams made up of experts in different specialized astrophysical fields, linguists, and journal editors (Méndez \& Alcaraz, 2015). Furthermore, Alla, Polina, Elizaveta, and Olga (2020) stated that, from a cognitive perspective, abbreviations were focused on the process of codification and preservation at the mental level, particularly in their creation and functioning.

In this regard, we admitted that abbreviations and the research value hidden behind them have huge research value. However, regardless of size or research topic, the current studies all had some limitations. Because Sigacheva, Makayev, Makayeva, and Gainanova (2021) stated that there has not been enough research on abbreviations of professional terms in the field of materials science; and Alla, Polina, Elizaveta, and Olga (2020) believed that functional and semantic properties of abbreviations have not received the attention they deserve, despite the fact that abbreviations have been discussed in a number of scientific disquisitions. Furthermore, current studies have tended to use well-known linguistic theories and humanities representatives to analyze abbreviations (Alla , Polina, Elizaveta, \& Olga , 2020).

Therefore, some gaps have been identified, which can support us in further study to identify those students in China who would face semantic difficulties caused by abbreviations in Arabic economic and business terms.

\section{The Scope of Study}

As previously stated, current studies on abbreviations are primarily concerned with methods of language development (Alla , Polina, Elizaveta, \& Olga , 2020). To study abbreviations, we should work with analysis outside of linguistic boundaries, as well, bringing it to an interdisciplinary level of study (Alla , Polina, Elizaveta, \& Olga , 2020). While we would put abbreviations into terminological framework to study their semantics. Because abbreviations 
were from Arabic economic and business terms, which were limited to what appeared in the textbook named "Arabic Applied Texts in Economy and Business" (Hereinafter referred to as "the textbook") (Yang, 2014). The content of abbreviations in the textbook involved Incoterms, abbreviations of international institutions in the spheres of economy and business such as WTO (World Trade Organization) and APEC (Asia-Pacific Economic Cooperation), as well as other common abbreviations like GDP, and so on (Yang, 2014).

\section{Methodology}

The present study adopted quantitative methods using a quiz to collect 30 samples among undergraduates in China through the simple mathematical statistics. And using comprehensive analysis (Alla, Polina, Elizaveta, \& Olga , 2020) analyzed specific data within terminological frameworks with semantics, so that semantic challenges of abbreviations faced by university students can be clearly identified.

In terms of a data collection instrument, a short quiz was conducted to collect data. A quiz involved 3 questions carrying 3 options per question ( 9 abbreviations randomly selected from the textbook) to compose the single-choice question with definitive answers. The purposes of this quiz were to test students' abilities in matching full denominations with their abbreviations and to test students' understanding of abbreviations' "hidden" meanings. In other words, the latter purpose was to test students' understanding of Arabic economic and business terms.

As for the research procedure, 60 undergraduates in third grade of Arabic language were divided into two groups to take part in the process of research. Specifically, both groups had 30 male and female students. Group A was given the closed papers to complete the quiz within 20 minutes in class, which was from Xibei Minzu University; Group B completed the quiz online using mobile phones within 20 minutes in class from Jilin International Studies University. Although the same quiz and the same time were used for two groups, the different external conditions would cause some uncertainty for the final results. It means that the results in Group B may have identical quizzes due to the phone's ability to look for related information online during the test time, invalidating the statistical results. Our analysis would suggest using the data from Group A to obtain the most accurate test results.

In terms of the interdependence of cognitive, communicative, semantic, and functional elements, as well as the methodologies employed for analysis in modern linguistics, the subject of abbreviation study looked to be broad and complicated, requiring representation in the fields of integrated approaches (Alla , Polina, Elizaveta, \& Olga , 2020). In this regard, we would adopt comprehensive methods for data analysis from lexical semantic (Paradis, 2012; Stringer, 2019), terminological semantic (Wang \& Zhang, 2009), and comparative study (Sigacheva, Makayev, Makayeva, \& Gainanova, 2021; Ulitkin, Filipova, Ivanova, \& Babaev, 2020).

- The method of lexical-semantic analysis, including semantic relations and cognitive semantics, would be conducted with Part A to examine the inherent components of abbreviations' meaning and the semantic relations (Stringer, 2019) between the correct answers and other options. This is decided by options that may cause some confusion, like similarity or opposition, to the students in each question.

- The method of terminological semantic analysis from a terminological perspective 


\section{DEVELOPMENT}

Vol. 11, No. 1, 2022, E-ISSN: 2226-6348 @ 2022 HRMARS

would work with the examination procedure, which can be regarded as a supplementary for lexical semantics. In other words, the terminological semantic framework of Wang and Zhang (2009) was developed from lexical semantics, including "Specific Semantic Triangle", "Classifications of Terminological Semantics Based on the Semantic Web of Knowledge Ontology" and "Micro-Terminology Semantic Structures". In particular, "Classifications of Terminological Semantics Based on the Semantic Web of Knowledge Ontology" would be an important framework for conducting abbreviation analysis. Because this framework was "the biggest and the most fundamental problem for semantic classification, that is how to divide the categories scientifically, and how to divide the major categories - medium categories - small categories - instance members according to the hierarchical relationship" (Wang \& Zhang, 2009). The following would show the diagram of example running in "Classifications of Terminological Semantics Based on the Semantic Web of Knowledge Ontology":

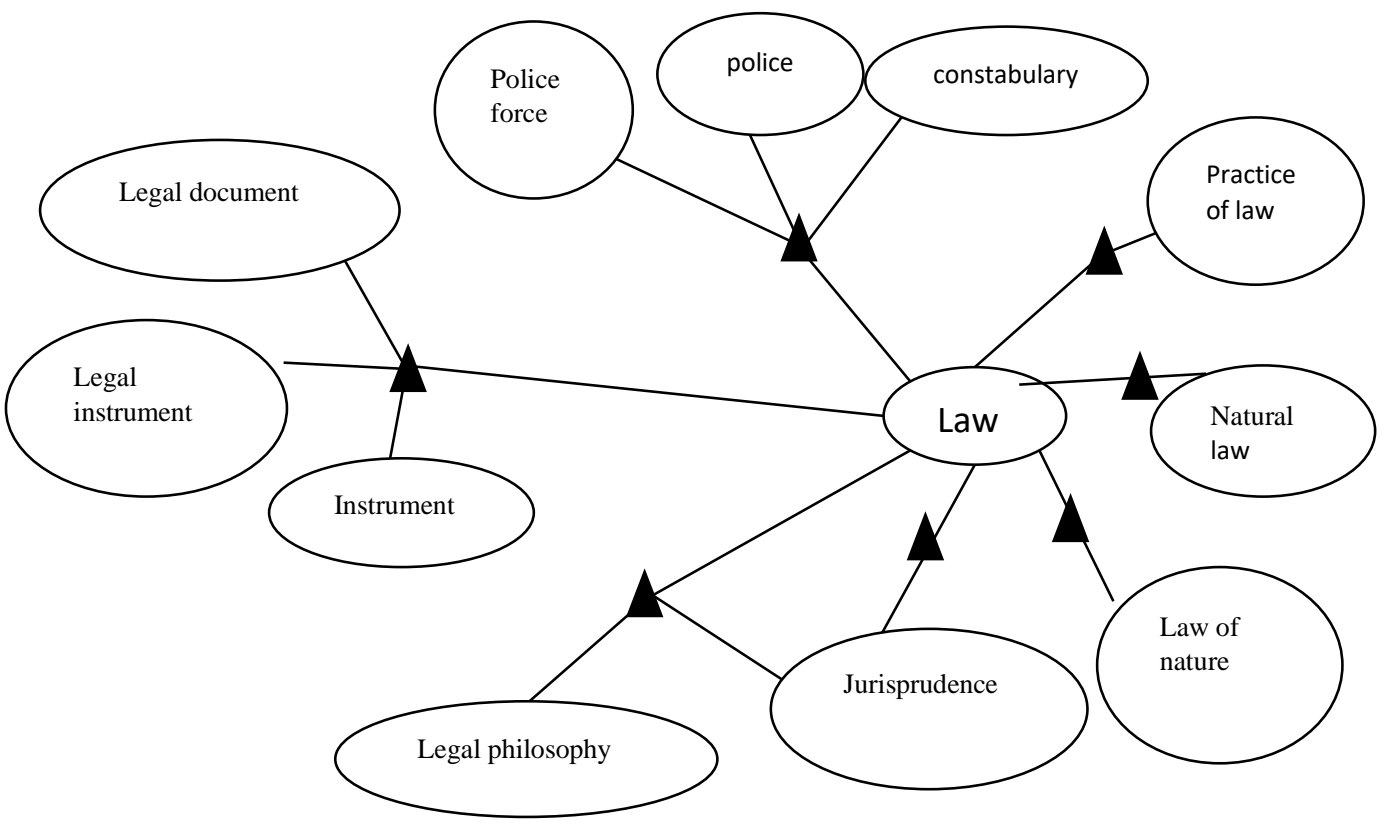

Figure 1: the diagram of example "law" running in "Classifications of Terminological Semantics Based on the Semantic Web of Knowledge Ontology"

Figure 1 shows the legal term "law" that constituted a local network of lexical items and meanings, reflecting a rigorous hierarchy and connection. This local lexical network followed a combination of linguistic and specialized ideas, and was not really a specialized terminology knowledge ontology, but the two embodied the same knowledge ontology semantic network characteristics. The solid triangles represent different meanings, and the different line shapes represent semantic relations such as "is a type of" and "parts of" (Wang \& Zhang, 2009). So, such a framework can be used as an example for abbreviations of Arabic economic and business terms. We could identify the abbreviations of Arabic economic and business terms that belong to specific topics and then adopt them to explain some unclear semantic relations between abbreviations.

- The comparative study (Sigacheva, Makayev, Makayeva, \& Gainanova, 2021; Ulitkin, Filipova, Ivanova, \& Babaev, 2020) mainly to compare the differences between correct 
abbreviations and wrong answers, so that the wrong reasons of students could be explored.

Therefore, as can be seen from the above list, some appropriate methods and techniques should be used in the research process in order to perform an abbreviated analysis based on an integrated approach to the linguistic phenomena under discussion.

\section{Results and Discussion}

The following paragraphs would describe the data results and discuss specific phenomena brought about by the results, which can reveal semantic challenges faced by students in understanding the abbreviations of Arabic economic and business terms.

The quiz had 3 questions, the stems were the full denominations of abbreviations, including (Gross Domestic Product, GDP), شعركة ذاتنات المحلي الإجمالي Company, LLC), and سعر ميناء الوصول (Cost, Insurance, and Freight, CIF). While the options showed some semantic relations between the correct answer and wrong answers.

Table 1 The overall situations in answering Part One

\begin{tabular}{|l|r|l|}
\hline No. questions & Wrong options & Selected frequencies \\
\hline 1 & GNPب & 5 \\
& GWPج & 0 \\
& PLLC & 4 \\
3 & LLP ج & 16 \\
& F.O. BI & 7 \\
& CAP ج & 0 \\
\hline The total correct & 25\% \\
answer rate (\%) & \\
\hline
\end{tabular}

Note: the wrong answers (abbreviations) were displayed in the table.

Table 1 showed the low correct rate for the quiz, at 25\%. The largest error was reported in Question 2, 20 times, in particular presented in the option Ltd. (16 times). The second error was shown in Question 3, at 7 times. Last, Question 1 presented a high rate of correct answers. Thus, the analysis will mainly focus on Question 2 below. In this light, the discussion would mainly focus on the comprehensive analysis between the option with the highest error rate and the correct option in each sub-question.

Question 1: the stem was الناتج المحلي الإجمالي (Gross Domestic Product), which was shortened to GDP. The table displayed the GNP was wrongly chose by students, at 5 times.

The stem الناتج المحلي الإجمالي (Gross Domestic Product) can be explained the following:

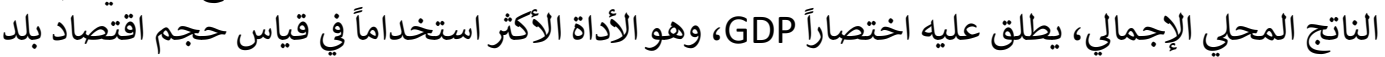

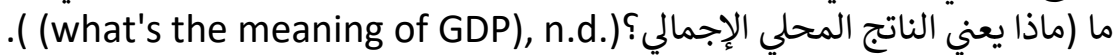

(Translating into English: "Gross domestic product (GDP) is the value of a nation's finished domestic goods and services during a specific time period" (Seth, 2021).)

While Gross National Product was shortened to GNP, the wrong abbreviation. The Arabic definition was: 


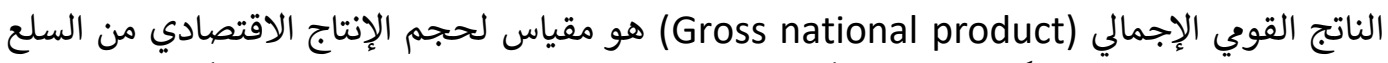

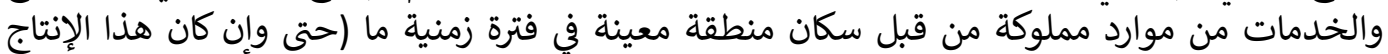

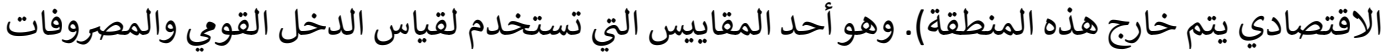

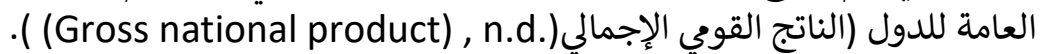

(Explaining in English: "the gross national product (GNP), is the value of all finished goods and services owned by a country's residents over a period of time" (Seth, 2021).)

In this light, the similarity between GDP and GNP in economics was that they were two of the most widely used economic indicators, both representing the total market value of all products and services produced over a specified time period (Seth, 2021). In contrast, there were differences in how each of them defined the scope of the economy. Basically, GDP measured the quantity of economic activity inside a country's economy, whereas GNP represented the value of economic activity created by the country's inhabitants. This implied that GNP would include the economic activities of expatriates and other citizens living beyond the country's boundaries, but GDP would not, and GDP would involve the activities of noncitizens living inside those limits, while GNP would not (MasterClass staff, 2021).

Specific to the semantic components, GDP and GNP were both adopted as "Macroeconomic indicators", which can be regarded as the core of knowledge ontology (Wang \& Zhang, 2009). GDP and GNP both belonged to two branches of the same triangle because they represented a common production category and a market value (Guanyu GDP \&GNP Naxie Shi, 2020). At the same time, the biggest difference between them was that GDP was a geographical concept, while GNP was a national concept. In this light, we thought students could not distinguish abbreviations of Arabic economic and business terms which they belonged to same core in knowledge ontology.

Question 2: the stem was شركة ذات مسؤولية محدودة (Limited Liability Company). And its abbreviation was מ. ش.ذ.م.م. أو ذ.م.م. (L.L.C). The above table showed that LLP was selected by four times as many people as PLLC. With that in mind, the erroneous reason for LLP may be explored below.

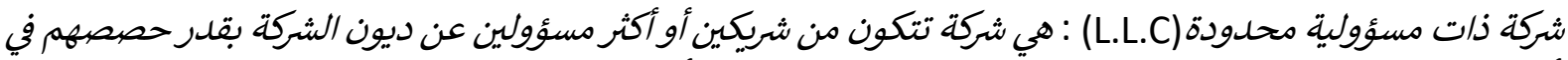

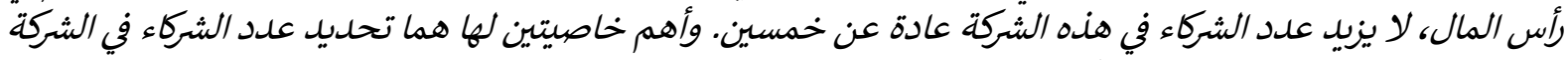

$$
\text { والمسؤولية المحدودة للشركاء .(الشكركة ذات المسؤولية المحلدودة، 2017) }
$$

L.L.C was illustrated in the limited liability company handbook in English by Sargent and Schwidetzky (2012):

It is a business structure in the United States whereby the owners are not personally liable for the company's debts or liabilities. Limited liability companies are hybrid entities that combine the characteristics of a corporation with those of a partnership or sole proprietorship (p.11).

While LLP represents شركة تضامنية محدودة المسؤولية (limited liability partnership) , which is a partnership in which some or all partners (depending on the jurisdiction) have limited liabilities (Sargent \& Schwidetzky, 2012).

In fact, they had a lot in common when it came to liability protection. Both an LLC and an LLP provided some personal liability protection by limiting each partner or member's 
responsibility to the amount they contributed in the firm. By contrast, the taxation revealed the distinction between LLC and LLP. A limited liability company (LLC) had the option of being taxed as a sole proprietorship, partnership, or corporation. An LLP, on the other hand, must file as a partnership. The method for selecting the management structure was also different between the two businesses. As previously stated, an LLC can only have one member, whereas an LLP required at least two partners (Mathias, n.d.).

Furthermore, while both were one of the business firms' forms, restricting accountability and tax flexibility may cause confusion among students. Because both have advantages and disadvantages in founding a corporation, there was therefore no absolute right choice between them. Corresponding to "Classifications of Terminological Semantics" in terminological semantic phenomenon (Wang \& Zhang, 2009), business firms' structures could be regard as a knowledge ontology, while LLC and LLP represented different meanings at the same level, having intersectoral parts.

Question 3: the stem was سعر ميناء الوصول (Cost, Insurance, and Freight), which was

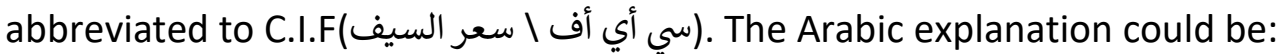

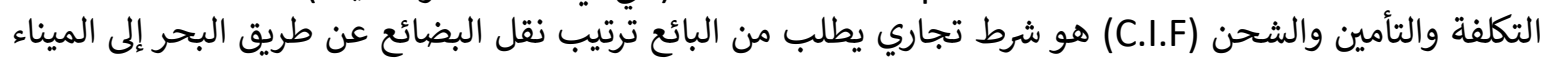

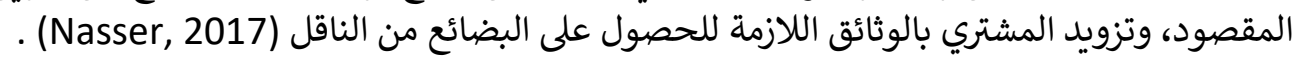
(It means in English that "an expense paid by a seller to cover the costs, insurance, and freight of a buyer's order while it is in transit" (Twin, 2021))

By contrast, F.O. B means تسليم على ظهر الباخرة أو سعر المغادرة اسعر الفوب (Free on Board). The Arabic explanation could be:

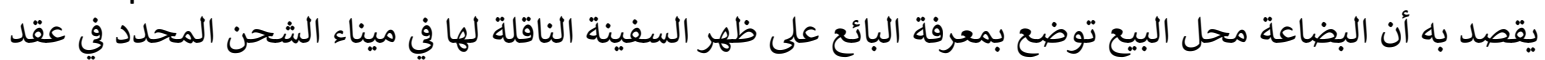

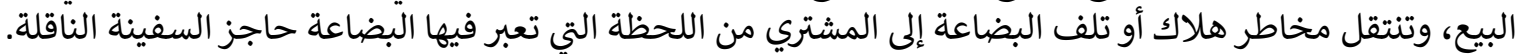
(Translating to English: "It is a designation that is used to indicate when liability and ownership of goods is transferred from a seller to a buyer" (What are FOB shipping terms?, 2009).)

The International Commerce Terms (Incoterms) CIF and FOB defined who was responsible for the products at each point along the transportation line. The main distinction between FOB and CIF was when obligation and ownership passed from one to the other. When a shipment left the point of origin, liability and title ownership moves in most circumstances of FOB. When the goods arrived at their destination, CIF passes responsibility to the buyer (What Is The Difference Between FOB and CIF?, n.d.). Thus, we supposed that CIF and FOB in semantics were relative antonyms.

In this regard, the overall results showed us that three-quarters of students had different semantic difficulties in understanding the abbreviations of Arabic economic and business terms. The main semantic challenges displayed First, it was difficult for students to distinguish similar abbreviations under the same semantic classifications with one knowledge ontology, which had subtle differences in semantics; secondly, relative antonyms for students were a noteworthy issue in handling semantic relations; thirdly, the "hidden" cognitive semantic challenge was to correspond to English abbreviations and full denominations in Arabic for students in China, since an abbreviation involved the comprehension of three languages. Hence, the cross-cultural semantic challenge was an invisible challenge penetrating abbreviations' learning. 
DEVELOPMENT

Vol. 11, No. 1, 2022, E-ISSN: 2226-6348 @ 2022 HRMARS

\section{Conclusion and Contribution}

The present study was mainly focused on finding semantic challenges caused by abbreviations of Arabic economic and business terms for undergraduates in China. The study has adopted a quantitative method to test 30 students using simple mathematical statistics and comprehensive analysis for the quiz analysis. The overall result showed that three-quarters of students had different semantic difficulties in understanding the abbreviations of Arabic economic and business terms.

The main semantic challenges mainly performed in:

1. it was difficult for students to distinguish similar abbreviations under the same semantic classifications with one semantic knowledge ontology, which had subtle differences in semantics, which performed in comparative analysis between correct answers and students' answers in Question1 and Question2;

2. relative antonyms for students were a noteworthy issue in handling semantic relations, which was shown in Question 3

3. the analysis results of three questions displayed that the "hidden" cognitive semantic challenge was to correspond to English abbreviations and full denominations in Arabic for students in China, since an abbreviation involved the comprehension of three languages. Hence, the cross-cultural semantic challenge was an invisible challenge penetrating abbreviations' learning.

Such semantic difficulties were caused by many aspects. For example, primarily, it may be due to the backgrounds of students who majored in Arabic language, rather than professions in the fields of economy and business; secondly, it may be because of ignorance of the instructors' teaching, since the forms of abbreviations look very simply.

Therefore, the contribution of our research would probably be to enhance undergraduates' understanding of abbreviations of Arabic economic and business terms in China, especially for those abbreviations within the same semantic knowledge ontology. Moreover, our study would not only benefit students, but also instructors, or even further study. For students, our study would remind them to focus on more relevant economic and business knowledge of abbreviations. Thus, students can enhance their performance in learning the textbook as well as using it correctly. For instructors, our study would provide a new teaching method when teaching such terms. In other words, our research methods, including comparing two terms in the same semantic context and explaining the concept of each term, can have an effect on the progress of teaching the textbook. For further study, our study has explored and used terminological semantic theories, which fill the gap in current semantic studies. And our study can be used as a reference for other further studies, if someone is interested in the same project. 
INTERNATIONAL JOURNAL OF ACADEMIC RESEARCH IN PROGRESSIVE EDUCATION AND

DEVELOPMENT

Vol. 11, No. 1, 2022, E-ISSN: 2226-6348 @ 2022 HRMARS

\section{Appendix}

List of abbreviations

\begin{tabular}{|l|l|}
\hline The textbook & $\begin{array}{l}\text { Arabic Applied Texts in Economy and } \\
\text { Business }\end{array}$ \\
\hline Incoterms & International Commercial Term \\
\hline FOB & Free on Board \\
\hline CIF & Cost, Insurance and Freight \\
\hline CAP & Customer-arranged Pickup \\
\hline GDP & Gross Domestic Product \\
\hline GWP & Gross World Product \\
\hline GNP & Gross National Product \\
\hline PLLC & Professional Limited Liability Company \\
\hline LLP & Limited Liability Partnership \\
\hline LLC & Limited Liability Company \\
\hline
\end{tabular}

\section{Acknowledgement}

Upon the completion of this study, I would like to take this opportunity to express my deepest appreciation to my supervisory committee, Professor Dr. Mohd Azidan Abdul Jabar, and Dr. $\mathrm{Ng}$ Chwee Fang. I can write a much better paper with their help and guidance.They always encourage me and give me unlimited support to help me turn my ideas into reality. I am very grateful to them during my postgraduate studies.

\section{References}

Abbreviation. (n.d.). Retrieved from Powered by Oxford Lexico : https://www.lexico.com/en/definition/abbreviation

Acronym. (n.d.). Retrieved from Powered by Oxford Lexico: https://www.lexico.com/en/definition/acronym

Alla , P.-B., Polina, I., Elizaveta, A., \& Olga, D. (2020). Semantic and Cognitive Communicative Aspects of Abbreviation in the Modern English Discourse Varieties. International Journal of English Linguistics, Vol. 10, No. 1. Retrieved from https://doi.org/10.5539/ijel.v10n1p26

Fazeli, S. H. (2010). A Modern Approach to Application of Abbreviation and Acronym Strategy for Vocabulary Learning in. Language in India, 407-418.

Guanyu GDP \&GNP Naxie Shi. (2020). Retrieved from Zhihu: https://zhuanlan.zhihu.com/p/159053798

Han, R. (2019). Guoji Shangwu Xinhan Yongyu De Cihui Tezheng. Keji Shijie, p. 176+169. doi:10.19694/j.cnki.issn2095-2457.2019.35.081

Huang, H. (2015). Analysis on Training Mode of Business Arabic Talents. Guoji Shangwu-Duiwai Jingji Maoyi Daxue Xuebao, 151-160. doi:10.13509/j.cnki.ib.2015.01.016

Incoterms 2020 Certificate (INCO) Online - ICC Academy. (2021). Retrieved from EduMaritime: https://www.edumaritime.net/icc-academy/incoterms-2020-certificate-inco-online

MasterClass staff. (2021). Economics 101: What Is the Difference Between GDP and GNP? Retrieved from MasterClass: https://www.masterclass.com/articles/economics-101what-is-the-difference-between-gdp-and-gnp

Mathias, C. (n.d.). LLC vs. LLP: What Is the Difference? Retrieved from Nolo.com: https://www.nolo.com/legal-encyclopedia/Ilc-vs-Ilp-what-is-the-difference.html 
Méndez, D. I., \& Alcaraz, M. Á. (2015). The Use of Abbreviations in English-Medium Astrophysics Research Paper Titles: A Problematic Issue. Australian International Academic Centre, Australia, pp. 185-196. doi:10.7575/aiac.alls.v.6n.3p.185

Nasser, R. (2017). التكلفة والتأمين والشحن (cost,insurance, freight ). Retrieved from https://trading-

secrets.guru/\%D9\%85\%D8\%B5\%D8\%B7\%D9\%84\%D8\%AD\%D8\%A7\%D8\%AA/\%D8\%A7 \%D9\%84\%D8\%AA\%D9\%83\%D9\%84\%D9\%81\%D8\%A9-\%D9\%88\%D8\%A7\%D9\%84\%D8\% AA\%D8\%A3\%D9\%85\%D9\%8A\%D9\%86-\%D9\%88\%D8\%A7\%D9\%84\%D8\%B4\%D8\%AD\% D9\%86-cost-insurance-and-freight/

Olga, K. D., Anna, F. D., \& Natalia, A. A. (2015). Problems of the English abbreviations in medical translation. Procedia - Social and Behavioral Sciences199 ( 2015 ), 548 - 554. doi:10.1016/j.sbspro.2015.07.545

Paradis, C. (2012). Lexical Semantics. (C. A. Chapelle, Ed.) The encyclopedia of applied linguistics Wiley-Blackwell. doi:10.1002/9781405198431.wbeal0695

Sargent, M. A., \& Schwidetzky, W. D. (2012). Chapter1: Forms of business organizations. In The Limited Liability Company Handbook. CT Corporation.

Seth, S. (2021). GDP vs. GNP: What's the Difference? Retrieved from Investopedia: https://www.investopedia.com/ask/answers/030415/what-functional-differencebetween-gdp-and-gnp.asp

Sigacheva, N., Makayev, K., Makayeva, G., \& Gainanova, D. (2021). Some approaches to translation of professional terms abbreviation in materials science. E3S Web of Conferences 274, 12003 (2021), 1-7.

doi:https://doi.org/10.1051/e3sconf/202127412003

Stringer, D. (2019). Chapter7: Lexical Semantics: Relativity and Transfer. In E. Nabat, \& M. Wei (Eds.), Applied Linguistics for Teachers of Culturally and Linguistically Diverse Learners (pp. 180-203). IGI Global. doi:10.4018/978-1-5225-8467-4.ch007

Trask, L. (1997). Abbreviations. Retrieved from

https://www.sussex.ac.uk/informatics/punctuation/capsandabbr/abbr

Twin, A. (2021). Cost, Insurance, and Freight (CIF). Retrieved from Investopedia: https://www.investopedia.com/terms/c/cif.asp

Ulitkin, I., Filipova, I., Ivanova, N., \& Babaev, Y. (2020). Use and translation of abbreviations and acronyms in scientific texts. E3S Web Conf., 210 (2020) 21006, pp. 1-12. doi:https://doi.org/10.1051/e3sconf/202021021006

Vasuchenko, G. (2011). Business English Terminology Semantic Name-Giving. ВICHИK ДНІПРОПЕТРОВСЬКОГО УНІВЕРСИТЕТУ ЕКОНОМІКИ ТА ПРАВА ІМЕНІ АЛЬФРЕДА НОБЕЛЯ., рр. 164-169.

Wang, D., \& Zhang, Z. (2009). Shuyu Yuyixue De Sange Lilun Jidian. Yuwen Yanjiu, 1-8.

What are FOB shipping terms? (2009). Retrieved from Simple Studies (according made simple):

https://web.archive.org/web/20171206224006/http://simplestudies.com/what-arefob-shipping-terms.html

What Is The Difference Between FOB and CIF? (n.d.). Retrieved from Redwoodlogistics: https://www.redwoodlogistics.com/difference-fob-cif/

Yang, J. (2014). Arabic Applied Texts in Economy and Business. University of International Business and Economics Press.

Zakharenko, D. (n.d.). Translating Abbreviations. Retrieved from Translation Directory: https://www.translationdirectory.com/article1182.htm 
Zerkina, N., Kostina, N., \& Pitina, S. A. (2015). Abbreviation semantics. Procedia-Social and Behavioral Sciences, 137-142. doi:10.1016/j.sbspro.2015.07.497

Zhao, P., \& Wu, B. (2010). Shangwu Yingyu De Cihui Tezheng Fenxi. Changchun Shifan Xueyuan Xuebao (Renwen Shehui Kexue Ban), 115-117.

(Gross national product) . (n.d.). Retrieved from Marefa.org: https://www.marefa.org/\%D8\%A7\%D9\%84\%D9\%86\%D8\%A7\%D8\%AA\%D8\%AC_\%D8 \%A7\%D9\%84\%D9\%82\%D9\%88\%D9\%85\%D9\%8A_\%D8\%A7\%D9\%84\%D8\%A5\%D8\%AC \%D9\%85\%D8\%A7\%D9\%84\%D9\%8A

ماذا يعني الناتج المحلي الإجمالي؟(what's the meaning of GDP). (n.d.). Retrieved from Alarabiya: https://www.alarabiya.net/aswaq/economic-

terms/2017/08/20/\%D9\%85\%D8\%B0\%D8\%A7-\%D9\%8A\%D8\%B9\%D9\%86\%D9\%8A-\%D 8\%A7\%D9\%84\%D9\%86\%D8\%A7\%D8\%AA\%D8\%AC-\%D8\%A7\%D9\%84\%D9\%85\%D8\%A D\%D9\%84\%D9\%8A-\%D8\%A7\%D9\%84\%D8\%A5\%D8\%AC\%D9\%85\%D8\%A7\%D9\%84\%D9 $\% 8 \mathrm{~A} \% \mathrm{D} 8 \% 9 \mathrm{~F}$ 